\title{
Absence of Ganglionated Plexus in Bullfrog Gallbladder
}

\author{
Masahide YoshidA ${ }^{1}$ and Takemi KoEDA ${ }^{2}$ \\ ${ }^{1}$ Biology Laboratory, Kanagawa Prefectural College of Nursing and Medical \\ Technology, 1-5-1 Nakao, Asahi-ku, Yokohama, 241-0815 Japan \\ ${ }^{2}$ Department of Pathology, Showa University School of Medicine, 1-5-8 \\ Hatanodai, Shinagawa-ku, Tokyo 142-0064 Japan
}

\begin{abstract}
We first carried out microscopic observation of the intramural nerves of a bullfrog gallbladder which were fixed and stained with a solution of $\mathrm{OsO}_{4}$ and $\mathrm{ZnI}_{2}$. We then investigated if the responses of isolated frog gallbladder evoked by electrical stimulation are mediated through the intramural nerves. The following results were obtained: 1 . The nerve plexus and the perivascular nerves were observed in the subserosal layer of the wall of the gallbladder. These nerves do not have a ganglia. That is to say, no ganglionated plexus or ganglia were observed in the subserosal layer of the wall of the gallbladder. 2 . Electrical stimulation caused the gallbladders to contraction with rectangular pulses (50 volt, $40 \mathrm{~Hz}$ ) of durations of $0.5,1,2,3,4$ and $5 \mathrm{msec}$ for a period of $10 \mathrm{sec}$. Three blockers of nerve-mediated responses, atropine $\left(1 \times 10^{-6} \mathrm{M}\right)$, guanethidine $\left(1 \times 10^{-6} \mathrm{M}\right)$ and tetrodotoxin $\left(3 \times 10^{-7} \mathrm{M}\right)$, had no effect on the gallbladder contractions induced by stimulation with pulses as short as $0.5 \mathrm{msec}$ or as long as $5 \mathrm{msec}$. These results suggest that the bullfrog gallbladder may not contain nerves related to movement. Thus, the contraction of the bullfrog gallbladder induced by electrical stimulation does not seem to be modulated by extrinsic nerve terminals distributed in the gallbladder wall.
\end{abstract}

Key words: frog gallbladder, intramural nerve, contraction, ganglia, nerve plexus

\section{Introduction}

Gallbladder motility is modulated by intramural cholinergic neurons of the gallbladder (Yau et al., 1984 and Brotschi et al., 1990). It appears, however, that detailed information on the nerves of the frog gallbladder as well as the relationship between gallbladder motility and gallbladder nerves remains scarce.

The following experiment was designed for two objectives: (1) to observe the intramural nerves of the frog gallbladder microscopically; and (2) investigate if the responses of isolated frog gallbladder evoked by electrical stimulation are mediated through its intramural nerves.

Correspondence to : Masahide Yoshida, Biology Laboratory, Kanagawa Prefectural College of Nursing and Medical Technology, 1-5-1 Nakao, Asahi-ku, Yokohama, 241-0815 Japan. 


\section{Materials and Methods}

\section{Animals}

Male and femal bullfrogs, Rana Catesbeiana, weighing 250 300 g, were used in our experiment.

\section{Microscopic observation of the intramural nerves}

Five bullfrogs were used for microscopic observation of the intramural nerves. A gallbladder with liver fraction was quickly excised and immediately immersed in Ringer solution. Isolated gallbladder was spherical in shape and its cystic duct was not observed. The bile duct and liver fraction were attached to the cervical surface of the gallbladder. The cystic duct, 0.5 $\mathrm{mm} \sim 1 \mathrm{~mm}$ in length and $1 \mathrm{~mm}$ in width, was connected to the bile duct when this region was carefully incised with scissors in Ringer solution. The duct was cut and then the gallbladder separated intact from the bile duct and liver fraction though a small hole made on the cervix of the gallbladder. The gallbladder was immediately fixed and stained by Sutherland's osmium tetroxide zinc-iodide method (1963). The following solutions were used in its method: 1) $0.5 \mathrm{~g}$ of $\mathrm{OsO}_{4}$ was dissolved in $25 \mathrm{ml}$ of distilled water. 2) $2.25 \mathrm{~g}$ of $\mathrm{ZnI}_{2}$ was dissolved in 75 $\mathrm{ml}$ of distilled water and filtered. These solutions were mixed immediately prior to use.

The isolated gallbladder was distended with a proper quantity of mixed solution injected with a polyethylene syringe via a small hole as mentioned above and the hole was immediately closed with a thread. It was then placed in remainder of the mixed solution in the dark for 1012 hoursto be fixed and stained. After that the portion of the gallbladder tied with the thread was removed and the gallbladder was longitudinally divided into two parts of approximately equal size. The mucosal layer of each preparation was then carefully scraped off in the mixed solution using a cotton wool topped rod and a pincett. Each preparation was briefly washed in distilled water, dehydrated with ethanol, cleared with xylol, expanded evenly and mounted in resin according to the procedure reported by Yoshida and Tsuruta (1988). Next, these preparations were viewed through a photomicroscope to observe the intramural nerves of the gallbladder.

\section{Responses of the gallbladder to electrical stimulation}

The gallbladder was removed intact as described in the "Microscopic observation of the intramural nerves" section, immersed in Ringer solution, and longitudinally divided into two approximately equal parts. Both pieces was used as a preparation. Each preparation was mounted in an organ bath filled with Ringer solution maintained at $23^{\circ} \mathrm{C}$ and gassed with $95 \%$ $\mathrm{O}_{2}$ and $5 \% \mathrm{CO}_{2}$ ( $\mathrm{pH}$ 7.4). The composition of the Ringer solution (mM) was as follows : 81.74 $\mathrm{NaCl}, 3.35 \mathrm{KCl}, 2.7 \mathrm{CaCl}_{2}, 22.30 \mathrm{NaHCO}_{3}$ and 5.5 glucose. As described by Yoshida and Ishiura (1981), the fundus of the gallbladder was fixed with pins and the cervical end was connected to a force displacement transducer with a silk thread. The mechanical response of the preparations evoked by electrical stimulation was recorded isometrically under a load of 1 g. Two platinum plates $(5 \mathrm{~mm} \times 5 \mathrm{~mm})$ were used as stimulus electrodes. The electrodes were placed, one on the serosal side and the other on the mucosal side of the preparation as 
described in our previous report (1981). The space between the preparation and electrode on the mucosal side was approximately $2 \mathrm{~mm}$. The electrode on the serosal side was placed very close, nearly touching, to the preparation. The preparation was electrically stimulated with rectangular pulses $(50$ volt, $40 \mathrm{~Hz}$ ) of durations of $0.5,1,2,3,4$ and $5 \mathrm{msec}$ for a period of 10 seconds and mechanical responses of the gallbladder were observed.

The drugs used were atropine sulfate, guanethidine sulfate and tetrodotoxin, and their concentrations are given in the Results section.

\section{Results}

\section{Observation of the intramural nerves of the gallbladder}

Using the osmium tetroxide zinc-iodide method (Sutherland, 1963), the intramural nerves of the gallbladder of a bullfrog were stained uniformly black. The background tissue of the intramural nerves was a yellowish-brown. The underlayer of this background tissue was a mucosal layer which was stained deep black. This mucosal layer was scraped off in our experiment as described in the "Materials and Methods" section. The black-stained intramural nerves of bullfrog gallbladders were observed as follows. The nerve plexus was observed in the bullfrog gallbladder wall (Fig. 1). The perivascular nerves which run parallel to and around blood vessels in the gallbladder wall were also observed in the same layer that contained the nerve plexus (Fig. 1). The perivascular nerves were connected with nerve bundles of the nerve plexus in the several places of the gallbladder wall (Fig. 1). Neither nerve plexuses nor perivascular nerves possessed ganglia (Fig. 1).

\section{Responses of the bullfrog gallbladders to electrical stimulation}

The bullfrog gallbladder contracted when exposed to electrical stimulation with rectangular pulses. As stimulus pulse-duration increased, the amplitude of contractions also increased until they reached a maximum at about $4-5$ msec durations (Fig. 2).
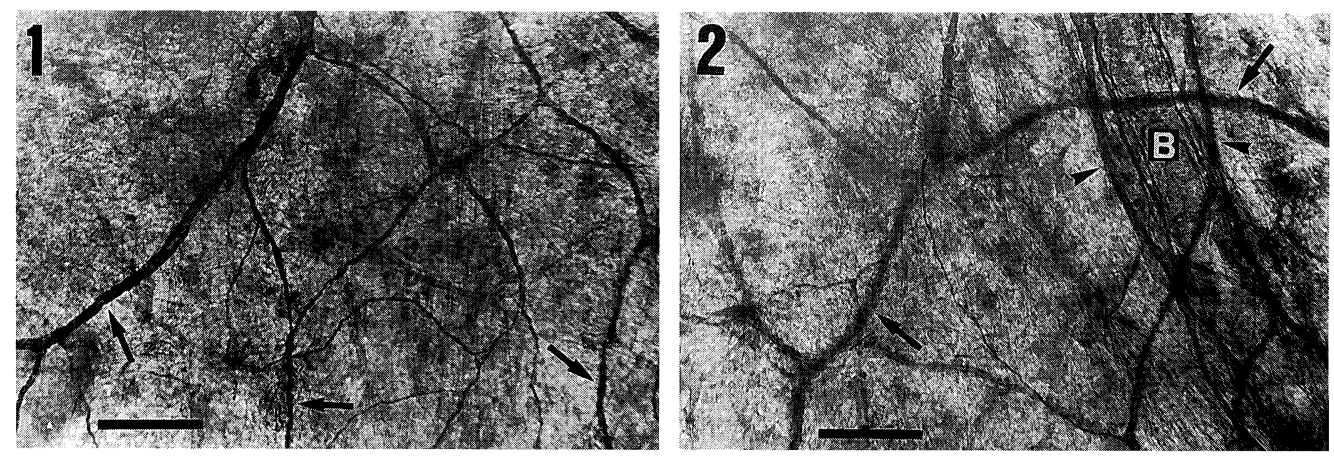

Fig. 1. Nerve plexus and perivascular nerve observed in the wall of the bullfrog gallbladder. B : blood vessel, Arrow: nerve bundle in the nerve plexus, Arrow head: perivascular nerve, Bar : $100 \mu \mathrm{m}$ 


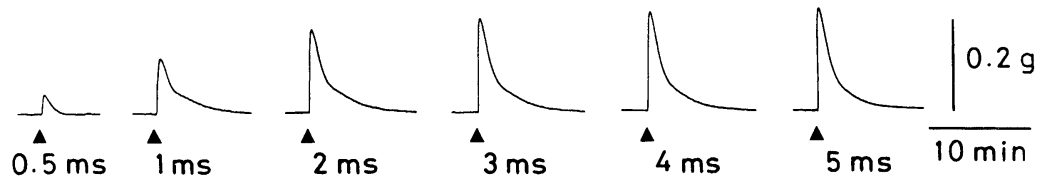

Fig. 2. Responses of the bullfrog gallbladder to electrical stimulation.

Electrical stimulation was applied to the gallbladder with rectangular pulses (50 volt, 40 $\mathrm{Hz}$ ) of durations of $0.5,1,2,3,4$ and $5 \mathrm{msec}$ for a period of $10 \mathrm{sec}$. Electrical stimulation was applied at triangular dot. The pulse duration of electrical stimulation is shown beneath the triangular dot. ms: msec.

Effects of atropine, guanethidine and tetrodotoxin on bullfrog gallbladder contractions induced by electrical stimulation

The effects of atropine, guanethidine and tetrodotoxin, which are blockers of nervemediated responses, on gallbladder contractions induced by electrical stimulation were also examined.

As shown in Table 1, atropine $\left(1 \times 10^{-6} \mathrm{M}\right)$, guanethidine $\left(1 \times 10^{-6} \mathrm{M}\right)$ and tetrodotoxin $(3 \times$ $\left.10^{-7} \mathrm{M}\right)$ had no effect on the contractions induced by pulses as short as $0.5 \mathrm{msec}(P>0.05$, respectively). At the above-mentioned concentrations, these three drugs still had no effect on contractions induced by pulses as long as $5 \mathrm{msec}(P>0.05$, respectively).

\section{Discussion}

In a study on the gallbladders of monkeys, cats, and guinea-pigs, Sutherland (1967) stated there is a well developed subserosal layer of areol tissue in the wall of the gallbladder. In this layer, in close proximity to the underlying muscular layer, lies the intramural nerves, that is, the ganglionated plexus and perivascular nerves. There is only one layer of muscular tissue which is incomplete: the muscle bundles that form a latticework with connective tissue, including elastic fibers filling the interstics. Beneath this layer is more areolar tissue forming a lamina propria to which the mucous membrane is connected. The submucosal plexus lies in

Table 1. Effects of atropine, guanethidine and tetrodotoxin on contractions of the bullfrog gallbladder induced by electrical stimulation

\begin{tabular}{cccc}
\hline $\begin{array}{c}\text { Pulse dura- } \\
\text { tion (msec) }\end{array}$ & Drugs & $\begin{array}{c}\text { Concentration } \\
(\mathrm{M})\end{array}$ & $\begin{array}{c}\text { Amplitude of contraction } \\
\text { (\% of control) }\end{array}$ \\
\hline \multirow{2}{*}{0.5} & Atropine & $1 \times 10^{-6}$ & $101 \pm 6$ \\
& Guanethidine & $1 \times 10^{-6}$ & $101 \pm 3$ \\
& Tetrodotoxin & $3 \times 10^{-7}$ & $101 \pm 3$ \\
\hline \multirow{2}{*}{5.0} & Atropine & $1 \times 10^{-6}$ & $102+6$ \\
& Guanethidine & $1 \times 10^{-6}$ & $103 \pm 5$ \\
& Ttetrodotoxin & $3 \times 10^{-7}$ & $102 \pm 4$ \\
\hline
\end{tabular}

The preparation was electrically stimulated with rectangular pulses (50 volt, $40 \mathrm{~Hz}$ ) of durations of $0.5 \mathrm{msec}$ and $5 \mathrm{msec}$ for a period of $10 \mathrm{sec}$. Each value represents the mean \pm S.D. $(n=8)$ of responses observed $20 \mathrm{~min}$ after administering the drug. None of the values showed singificant differences from those before administering the drug, namely from the control, at $P<0.05$. 
this areolar tissue. Since the mucous membrane was scraped off in our experiment, the yellowish-brown background tissue of the intramural nerves observed in our experiment might correspond to the muscle bundle and connective tissue. Also, the intramural nerves appear to lie in the subserosal layer of the wall of the gallbladder as above-mentioned.

No ganglionated plexus was observed in the bullfrog gallbladder wall, but a nerve plexus was (Fig. 1). The perivascular nerves which run parallel to and around blood vessels were also observed in the wall (Fig. 1). These perivascular nerves did not have of ganglia (Fig. 1). The nerve plexus and perivascular nerves appeared to lie in the subserosal layer of the gallbladder wall, as mentioned above. Since the mucosal layer was scraped off in our experiment, it was impossible to observe nerves in the submucosal layer. These results might correspond to observation of the subserosal layer of guinea-pig gallbladders by Sutherland (1967) and Cai and Gabella (1983), except that no ganglia were observed in subserosal layer. It is well-known that the ganglionated plexus or ganglia are present in the wall of monky, cat, guinea-pig and human gallbladders (Alexander, 1940 ; Burnett, et al., 1964 ; Sutherland, 1966, 1967 ; Miyazaki and Onda, 1980 ; Cai and Gabella, 1983 ; Yoshida and Tsuruta, 1988). It will be, therefore, careless to conclude that the ganglionated plexus or ganglia are definitely absent in the subserosal layer of the bullfrog gallbladder wall based only on our results. It can be assumed, however, that they are likely absent.

In pharmacological analyses of electrical stimulation-induced responses of isolated guineapig gallbladders, Lee and Fujiwara (1973) and Yoshida and Ishiura (1983) demonstrated that the guinea-pig gallbladder contained cholinergic excitatory nerves. Further, in pharmacological analyses of electrical stimulation-induced response, Yanaura and Ishikawa (1975) in a report on isolated guinea-pig and rabbit gallbladders, and Davison et al. (1978) in a report on the guineapig gallbladder, suggested that the gallbladder may contain cholinergic excitatory nerves and non-adrenergic inhibitory nerves. Electrical stimulation-induced contractile responses of the guinea-pig gallbladder are primarily mediated by activation of postganglionic cholinergic neurons (Parkman et al., 1997). These findings indicate the possibility that the movement of the gallbladder is neurogenically controlled. Furthermore, several lines of evidence indicate that the ganglionated plexus plays a crucial role in the regulation of smooth muscles in the gallbladder. For example, circulating hormones such as cholecystokinin appears to act within the ganglia to cause the gallbladder to contract (Bauer et al., 1991; Hanyu et al., 1990 ; Mawe, 1991 ; Mawe et al., 1994, 1997 ; Takahashi et al., 1991).

In the present study, electrical stimulation caused bullfrog gallbladder muscles to contract (Fig. 2). It is generally accepted that intramural nerves of tissues with smooth muscle are stimulated by electrical stimulation with pulses of short-duration (1 msec or less) (Suzuki, 1974). Three blockers of nerve-mediated responses, atropine $\left(1 \times 10^{-6} \mathrm{M}\right)$, guanethidine $\left(1 \times 10^{-6} \mathrm{M}\right)$ and tetrodotoxin $\left(3 \times 10^{-7} \mathrm{M}\right)$, had no effect on contractions of the gallbladder induced by the stimulation with pulses as short as $0.5 \mathrm{msec}$ and as long as $5 \mathrm{msec}$ (Table 1). It is therefore reasonable to consider that contractions of the bullfrog gallbladder induced by electrical stimulation with pulses of $0.5 \mathrm{msec}$ or more are not mediated by a direct effect of the current on the intramural nerves of the gallbladder, but are mediated directly by the current on the gallbladder muscle. That is to say, no contractions caused by intramural nerves were observed 
in the bullfrog. In this way contractions in bullfrogs differ significantly from those in the guinea-pig gallbladder, which has a ganglionated plexus, but are similar to those in hamster and mouse gallbladders, which do not have a ganglionated plexus or ganglia (Yoshida and Koeda, 1991 ; 1992). These results suggest that the bullfrog gallbladder may not contain nerves involved in movement.

In conclusion, the contraction of the bullfrog gallbladder induced by electrical stimulation dose not seem to be modulated by extrinsic nerve terminals distributed in the gallbladder wall.

\section{References}

Alexander, W.F. (1940). The innervation of the biliary system. J. Comp. Neurol. 72: 357-370.

Bauer, A.J., Hanani, M., Muir, T.C., and Szurszewski, J.H. (1991). Intracellular recordings from gallbladder ganglia of opossums. Am. J. Physiol. 260 : G299-G306.

Brotschi E.Z., Pattavino, J. and Williams, L.F. (1990). Intrinsic nerves affect gallbladder contraction in the guinea pig. Gastroenterology $99: 826-830$.

Burnett, W., Gairns, F.W. and Bacsich, B.P. (1964). Some observations on the innervation of the extrahepatic biliary system in man. Annals of Surgery 159:8-26.

Cai, W. and Gabella, G. (1983). Innervation of the gallbladder and biliary pathways in the guineapig. J. Anat. 136 : 97-109.

Davison, J.S., Al-Hassani, M., Crowe, R. and Burnstock, G. (1978). The non-adrenergic, inhibitory innervation of the guinea-pig gallbladder. Pflügers Arch. 377: 43-49.

Hanyu, N., Dodds, W.J., Layman, R.D., Hogan, W.J., Chey, W.Y. and Takahashi, I. (1990). Mechanism of cholecystokinin-induced contraction of the opossum gallbladder. Gastroenterology 98: 1299-1306.

Lee, W.H. and Fujiwara, M. (1973). Effect of catecholamines on the contractile response of isolated guinea-pig gallbladder to transmural and chemical stimulation. Jiritsushinkei (Japan) 10 : 102-106.

Mawe, G.M. (1991). The role of cholecystokinin in ganglionic transmission in the guinea-pig gallbladder. J. Physiol. (London) 439: 89-102.

Mawe, G.M., Gokin, A.P., and Wells, D.G. (1994). Actions of cholecystokinin and norepinephrine on vagal inputs to ganglion cells in guinea pig gallbladder. Am. J. Physiol. 276 : G1146-G1151.

Mawe, G.M., Talmage, E.K., Cornbrooks, E.B., Gokin, A.P., Zhang, L., and Jennings, L.J. (1997). Innervation of the gallbladder: Structure, neurochemical coding, and physiological properties of guinea pig gallbladder ganglia. Microscopy Reseach and Techique 39: 1-13.

Miyazaki, T. and Onda, M. (1980). The adrenergic and cholinergic innervation of gallbladder and extrahepatic biliary duct system in the cat and human. Nippon Shokakibyo Gakkai Zasshi 77 : 935-948.

Parkman, H.P., Pagano, A.P., Martin, J.S. and Ryan, J.P. (1997). Electric field stimulation-induced guinea pig gallbladder contractions: Role of calcium channels in acetylcholine release. Digestive Diseases and Sciences 42: 1919-1925.

Sutherland, S.D. (1963). The use of zinc iodide in the Champy osmic acid technique. J. Anat. 97 : 624-625.

Sutherland, S.D. (1966). The intrinsic innervation of the gallbladder in Macaca rhesus and Cavia porcellus. J. Anat. $100: 261-268$.

Sutherland, S.D. (1967). The neurons of the gallbladder and gut. J. Anat. 101: 701-709.

Suzuki, T. (1974). The mechanism of inhibition. In: Pharmacology and physiology of the smooth muscle, ed. by Bando, T., Takagi, K. and Ebashi, S., Nankodo, Japan (in Japanese), pp. 99- 
115.

Takahashi, T., May, D., and Owyang, C. (1991). Cholinergic dependence of gallbladder response to cholecystokinin in the guinea pig in vivo. Am. J. Physiol. 261: G565-G569.

Yau, W.M. and Youther M.L. (1984). Modulation of gallbladder motility by intrinsic cholinergic neurons. Am. J. Physiol. 247 : G662-G666.

Yoshida, M. and Ishiura, S. (1981). Transmural electrical stimulation-induced relaxation of the guinea-pig gall bladder. J. Pharm. Dyn. 4 : 751-758.

Yoshida, M. and Tsuruta, Y. (1988). Observation on the distribution of ganglia in the ganglionated plexus of guinea-pig gallbladder. Jpn. J. Smooth Muscle Res. 24 : 113-125.

Yoshida, M. and Koeda, T. (1991). Studies on the intramural nerves of the hamster and mouse gallbladders. J. Smooth muscle Res. 27 : 23-34.

Yoshida, M. and Koeda, T. (1992). Studies on the electrical stimulation-induced contractile responses of hamster and mouse gallbladders. J. Smooth Muscle Res. 28: 111-120.

(Received November 4, 1998 : Accepted December 15, 1998) 